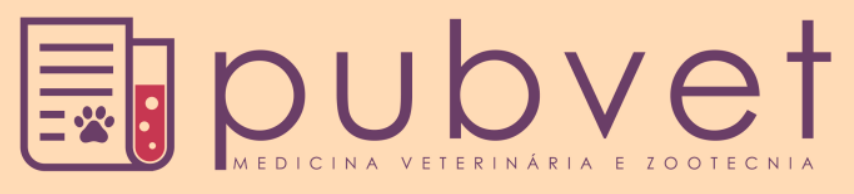

ISSN $1982-1263$

https://doi.org/10.22256/pubvet.v12n5a94.1-8

\title{
Aplicação das boas práticas agrícolas na produção de leite
}

\author{
Izabel Bastos Pereira Neta* ${ }^{\bullet}$, Adriana Rodrigues da Silva ${ }^{\ominus}$, Giselly Monique do Carmo \\ Santos $^{\ominus}$, Thaynná Silva Athiê ${ }^{\ominus}$, Wiviane Cristina Silva Reis ${ }^{\bullet}$, Vitória Nazaré Costa \\ Seixas ${ }^{\bullet}$
}

${ }^{1}$ Universidade do Estado do Pará, Avenida Hiléia, Agropolis do Incra, s/n, Bairro Amapá, Marabá-PA, 68502-100, Brasil.

*Autor para correspondência, E-mail: izabelbastos@ymail.com

\begin{abstract}
RESUMO. O estudo objetivou avaliar as condições microbiológicas e de conservação, para as Boas Práticas Agrícolas (BPA) na produção do leite. A higiene durante o processo de obtenção e armazenamento do leite na propriedade leiteira pode ser averiguada por meio da Contagem de Bactérias Totais e da Contagem de Células Somáticas. O desenvolvimento da cadeia de produção de leite seguido da qualidade desejada para o produto são desafios dos produtores rurais, a fim de garantir ao consumidor um produto seguro, nutritivo e saudável, isentos de contaminação microbiológica. Com isso, a execução das BPA's, desde o momento da ordenha até a sua chegada à granja leiteira para seu beneficiamento é importante evitando possíveis contaminações durante o processo de obtenção do produto final. Portanto devem-se seguir padrões de qualidade para obtenção de uma boa matéria prima.
\end{abstract}

Palavras chave: bovinocultura, higiene, qualidade

\section{Implementation of good agricultural practices in the production of milk}

ABSTRACT. The study aimed to assess the microbiological conditions and conservation, to the Good Agricultural Practices (GAP) in the production of milk. Hygiene during the process of obtaining and storage of milk in the dairy property can be determined by using the total bacteria count and Somatic cell count. The development of milk production chain followed by the desired quality for the product are challenges of rural producers, in order to guarantee the consumer a product safe, nutritious and healthy, free from microbiological contamination. With that, the implementation of the BPA's, from the moment of your arrival to the milking to dairy farm for your processing is important to preventing possible contamination during the process of obtaining of the final product. Therefore should follow standards for obtaining a good raw material.

Keywords: cattle, hygiene, quality

\section{Aplicación de las buenas prácticas agrícolas en la producción de leche}

RESUMEN. El estudio pretende evaluar las condiciones microbiológicas y conservación, a las buenas prácticas agrícolas (BPA) en la producción de leche. Higiene durante el proceso de obtención y almacenamiento de la leche en la lechería propiedad puede determinarse mediante el uso de la cuenta total de bacterias y células somáticas. El desarrollo de la cadena de producción de leche seguido de la calidad deseada para el producto son retos de los productores rurales, a fin de garantizar al consumidor un producto 
seguro, nutritivo y saludable, libre de contaminación microbiológica. Con esto, la implementación de las BPA, desde el momento de su llegada a la ordeña a granja de productos lácteos para su procesamiento es importante para prevenir la posible contaminación durante el proceso de obtención del producto final. Por lo tanto debe seguir las normas para la obtención de una buena materia prima.

Palabras clave: ganado, higiene, calidad

\section{Introdução}

O leite é uma matéria-prima destinada a distintas indústrias visando à obtenção de produtos derivados como queijos, fermentados, leites, pasteurizado, doces, UHT, entre outros. A qualidade do leite é um fator determinante para a segurança desses produtos. Vários fatores interferem na qualidade do leite, como raça, genética, alimentação, manejo, etc., no entanto, é no processo de aquisição que reside hoje uma das principais limitações para se produzir leite com qualidade. Existem regulamentações para melhorar a qualidade do leite, porém o problema ainda persiste, principalmente devido a muitas ações propostas não alcançarem o pequeno produtor (Nascimento \& Raszl, 2012).

Sendo o leite definido como o produto oriundo da ordenha completa e ininterrupta, em condições de higiene, de vacas sadias, bem alimentadas e descansadas (Brasil, 2011). Essa matéria-prima está entre os seis produtos mais importantes da agropecuária brasileira. A comercialização do leite e seus derivados exercem um papel importante no suprimento de alimentos e na geração de emprego e renda para a população (EMBRAPA, 2002).

O leite é uma mistura complexa de substâncias nutritivas e minerais que se encontram em diferentes estados, dispersos e em água, sendo alimento de alto valor nutritivo, podendo suprir quase todas as exigências nutricionais tanto do homem como doas animais. Sendo assim constitui-se um excelente meio para a proliferação de microrganismos (AGEITEC, 2012).

Em termos estruturais, mais de $90 \%$ do leite captado no $1^{\circ}$ trimestre de 2015 foi processado por laticínios que receberam mais de um milhão de litros de leite no trimestre, representados por menos de $1 / 3$ das indústrias lácteas que possuem registro em algum serviço de inspeção sanitária (IBGE, 2015).

A produção do leite in natura em condições higiênico-sanitárias impróprias torna-se um obstáculo para as indústrias lácteas, pois há uma diminuição no rendimento na produção dos derivados lácteos comprometendo também a qualidade do produto final (Ferreira et al.,2012).

Diante do exposto o presente artigo tem por objetivo apresentar a importância da aplicação das Boas Práticas Agrícolas na produção de leite.

\section{Boas Práticas Agrícolas}

As Boas Práticas Agropecuárias (BPA) é a parte fundamental que significa a utilização e a implementação de procedimentos adequados em todas as etapas de obtenção, produção, processamento, armazenamento, transporte $\mathrm{e}$ distribuição de matérias-primas, insumos e produtos agroalimentares, devendo ser mantidos desde os elos primários de produção a campo até os consumidores, fornecendo garantia de qualidade e de segurança assim como a agregação de valor ao sistema de produção de alimentos (Brasil, 2015).

Essas BPA vêm sendo implantadas na produção leiteira com a finalidade de garantir a segurança e a qualidade deste produto. Em sistemas de produção agroecológica isto se torna ainda mais importante, pois como é vedado o uso de medicamentos sintéticos, a adoção de práticas inadequadas de manejo pode dar origem a doenças crônicas como mastite, que terão forte impacto na qualidade final do leite (Juliano et al., 2015).

A higiene pessoal do ordenhador, o tratamento das vacas doentes, a limpeza e desinfecção diária de todos os equipamentos utilizados na ordenha são fatores decisivos para a melhora da qualidade bacteriológica do leite e garantia para os consumidores (Carvalho et al., 2013; Luz et al., 2011). O resfriamento do leite logo após essa ordenha, e a coleta granelizada, são importantes medidas para garantir essa qualidade microbiológica do leite (Nero et al., 2005).

A higienização dos tetos do animal a ser ordenhado deve sofrer prévia lavagem com água corrente, seguindo-se de secagem com toalhas descartáveis e início imediato da ordenha, com descarte dos jatos iniciais de leite em caneca de fundo escuro ou em outro recipiente específico para essa finalidade. Após a ordenha, devem-se 
desinfetar imediatamente os tetos com produtos apropriados, no qual os animais devem ser mantidos em pé pelo tempo suficiente para que o esfíncter da teta volte a se fechar. Para isso, recomenda-se oferecer alimentação no cocho após a ordenha (Brasil, 2011).

O mecanismo de ordenha executado na propriedade leiteira é de grande importância para manter a qualidade do leite, pois a ordenha é a última fase de uma sequência de etapas na produção de leite, que interfere de forma expressiva nas características da matéria-prima utilizada na fabricação de derivados lácteos (Carvalho et al., 2013). Para se evitar altas contagens bacterianas é preciso trabalhar com higiene e refrigerar o leite o mais rapidamente possível (Dürr, 2012).

A qualidade da matéria-prima com base nos parâmetros indicativos de rendimento ou da saúde do rebanho está sendo evidenciado através de um constante pagamento diferenciado do leite por indústrias de laticínios. A coleta de amostras de leite in natura deve ser rigorosa para que possa resultar a sua real composição (Cabral et al., $\underline{2013}$ ).

O sistema de ordenha adotado na propriedade leiteira é de importância para a melhoria da qualidade do leite, pois a ordenha é a última fase de uma sequência de eventos na produção de leite, que interfere de forma significativa na qualidade da matéria prima destinada a fabricação dos derivados lácteos, no qual é recomendado a adoção de algumas práticas para controlar a contaminação microbiológica, como manter o local de ordenha limpo, utilizar água potável, lavar as mãos e mantê-las limpas durante a ordenha (Brasil et al., 2012; Guido et al., 2010).

No momento da ordenha manual ou mecânica alguns procedimentos devem ser realizados, para assegurar a qualidade do leite e consequentemente dos seus derivados (EMBRAPA, 2011a):

- Verificar se os equipamentos, utensílios de ordenha e o tanque de refrigeração estão devidamente limpos e sanitizados;

- A higiene do ordenhador também é muito importante, deve-se lavar as mãos antes de iniciar a ordenha garantindo que o manipulador tenha hábitos apropriados de higiene e recebam treinamento para desempenhar suas atividades;

- É indicado retirar os três primeiros jatos de leite de cada teto em uma caneca de fundo preto ou telada e observa se há alguma alteração no aspecto do leite como a presença de grumos, pus, amarelado ou aquoso, se houver alguma dessas características é sinal de mastite clínica, após o teste em caso positivo para mastite o leite da teta afetada tem que ser descartado, em caso negativo deve-se secar os tetos com papel-toalha descartável;

- Lavar somente os tetos sujos evitando molhar o úbere, limpando especialmente as extremidades, usando mangueira de baixa pressão em seguida secálos;

- A desinfecção dos tetos antes da ordenha reduz a quantidade de bactérias que está na pele do animal, auxiliando na redução da CTB e dos casos de mastite. Antes de iniciar a ordenha, os tetos das vacas devem ser imersos em solução desinfetante apropriada, com formulação feita especialmente para a higienização dos tetos, ele deve cobrir totalmente a superfície do teto e atuar por no mínimo 30 segundos, o frasco utilizado deve ser do tipo sem retorno. Após a desinfecção secar completamente os tetos, usando papel toalha descartável. Iniciar a ordenha dentro de um minuto após a preparação do úbere, sem interrupções;

- Após o término da ordenha, é muito importante fazer a desinfecção dos tetos, para matar as bactérias que possam ter sido transmitidas por equipamentos, pelo ordenhador ou por outras vacas;

- Ao terminar a ordenha é indicado fornecer alimento no cocho para as vacas assim auxiliando elas se manterem de pé, com isso reduzindo a incidência de infecções intramamárias (IIM).

\section{Ordenha manual}

A ordenha manual é um método remoto de extração do leite, que é utilizado em propriedades leiteiras do país e pode ser tão higiênica e satisfatória que a ordenha mecânica sendo muitas vezes mais suave para o úbere. Apesar de ser considerado como um método antigo é possível produzir leite com qualidade, no qual se os procedimentos de ordenha estiverem corretos, as vacas podem dar mais leite, porém há uma problemática nas boas práticas agrícolas com a presença do bezerro ao pé, no momento da ordenha, o que dificulta o controle da higiene (Carvalho et al., 2013; DAIS, 2008). 
No processo manual deve-se ter cuidados especiais antes do início da ordenha como a limpeza das mãos e dos ante-braços do ordenhador para evitar a contaminação da bebida. A ordenha deverá ser realizada instantaneamente logo após a preparação do animal para melhor obtenção do leite devido a sua descida. O mais indicado na hora de fazer o manejo é ordenhar os tetos de modo cruzado e os dedos deverão envolver todo o teto pressionando de cima para baixo, com movimentos uniformes e sem puxar. Deve-se esgotar o úbere de maneira completa (Zafalon et al., 2008).

Nesse tipo de manejo é recomendado que ordenhador tenha atenção para com o leite evitando que sujidades externas tenha contato com a bebida, e os utensílios utilizados como baldes e latões deve ser de aço inoxidável em bom estado de conservação e de limpeza (PAS Campo, 2005).

\section{Ordenha mecânica}

Na ordenha mecânica o leite é ordenhado com maior rigor de higiene, nesta realiza-se o prédipping e pós-dipping, como forma de prevenção da incidência de mastite no rebanho (Carvalho et al., 2013). A eliminação dos três primeiros jatos de leite, usados no sistema do pré-dipping e pósdipping, apresenta uma rigorosa higiene durante a ordenha. A eliminação da água residual dos utensílios de ordenha são propostas simples, e devem ser incorporadas na rotina da propriedade leiteira, utilizada na prevenção de incidência de mastite no rebanho. Dessa forma há uma contribuição significativa para a melhoria da qualidade do leite (Melo et al., 2013).

É indicado que exerça a manutenção dos equipamentos e ao realizar a higienização nesses aparelhos deve utilizar produtos químicos específicos e apropriados para a limpeza do mesmo, seguindo as recomendações do fabricante ou assistência técnica. Retirar as teteiras a cada seis meses ou 2.500 ordenhas. Impedir que haja resíduos de leite ou de água nas tubulações, válvulas e nos insufladores de ar das teteiras; se houver algum resquício, proceder à circulação de água clorada ou à drenagem (PAS Campo, 2005).

Para que ocorra a melhoria da qualidade do leite cru refrigerado se faz necessárias medidas de incentivo aos produtores, como programas de pagamento por qualidade do leite, para que os esforços de técnicos, universidades e cooperativas na implantação de boas práticas de higiene na ordenha tenham melhor adesão dos produtores.
Análises realizadas em um expressivo número de propriedades, com as implantações das boas práticas de ordenha, observou-se a produção de leite cru refrigerado com padrão de qualidade internacional (Ribeiro Júnior et al., 2014).

O desenvolvimento da cadeia de produção de leite seguido da qualidade desejada para o produto são desafios para produtores rurais e para os elos que compõem a cadeia, a fim de garantir ao consumidor um produto seguro, nutritivo e saudável, isentos de contaminação microbiológica resultante de falhas na obtenção do leite, desde o manejo do gado, higienização correta na ordenha, coleta a granel, transporte e resfriamento (EMBRAPA, 2011b).

\section{Contagem de Bactérias Totais - CBT}

O parâmetro utilizado com maior frequência para avaliar a qualidade do leite durante a aquisição e acondicionamento é a Contagem Bacteriana Total (CBT), que significa o total de microrganismos aeróbios mesofilos, que ocorre na falta de condições básicas de higiene de uma maneira geral, bem como a falta de refrigeração do leite (Barancelli, 2002; Bava et al., 2009; Brasil et al., 2012).

A CBT avalia a qualidade microbiológica do leite, sendo as principais fontes de contaminação bacteriana as superfícies dos equipamentos de ordenha e tanque, superfície externa dos tetos e úbere e patógenos causadores de mastite no interior do úbere (Molineri et al., 2012). A higiene de ordenha tem importância, pois mesmo um leite produzido com baixas contagens será contaminado em um sistema canalizado quando não forem observadas as medidas de higiene na lavagem dos equipamentos assim como a troca periódica de alguns componentes do sistema (Saran Netto et al., 2009). É necessário o uso das práticas higiênicas, durante toda a etapa produtiva para que a indústria possa receber o leite granelizado com uma baixa CBT (Silva et al., $\underline{2010}$ ). A CBT está relacionada com higiene na ordenha, estoque e transporte do leite e, quando ela está alta, há degradação do produto, com consequente redução de sua vida de prateleira (Ribeiro Junior et al., 2015).

O valor superior admitido pela legislação é sugestivo de carência de cuidados na limpeza e higienização dos equipamentos utilizados na ordenha, do sistema de refrigeração, dos tetos, além da presença de mastite nas vacas. A higienização imprópria das superfícies de contato 
e a temperatura inapropriada de resfriamento tornam os equipamentos de ordenha $\mathrm{e}$ resfriamento veiculadores de bactérias no leite, ajustando um ambiente favorável para o desenvolvimento de biofilmes e ampliação da Contagem Bacteriana Total (Taffarel et al., 2013).

\section{Contagem de Células Somáticas - CCS}

A Contagem de Células Somáticas (CCS) está relacionada ao cuidado sanitário das glândulas mamárias de vacas leiteiras e correta manipulação dos utensílios de ordenha (Brasil et al., 2012). A CCS é a média geométrica sobre um período de três meses, com pelo menos uma análise mensal em Unidade Operacional da Rede Brasileira de Laboratórios para Controle da Qualidade do Leite, independentemente das análises realizadas na frequência estipulada pelo Programa de Controle de Qualidade interno da Granja Leiteira (Brasil, 2011).

A qualidade do leite pode ser afetada por diferentes fatores, no qual entre os mais significativos está a mastite, inflamação da glândula mamária causada, principalmente, por microrganismos que afeta a glândula mamária de fêmeas lactentes promovendo aumento na ocorrência de células somáticas no leite, que altera as características do leite e ocasiona danos econômicos expressivos para esta cadeia produtiva. Esse aumento na CCS está relacionado com queda na produtividade, além de alterações na composição do leite, na atividade enzimática, no tempo de coagulação, no rendimento industrial e na qualidade dos derivados lácteos. A inflamação do úbere da vaca deve ser reconhecida e tratada para não prejudicar a produtividade do rebanho (Andrade et al., 2014; Arashiro et al., 2006; Kitchen, 1981; Montanhini et al., 2013).

\section{Mastite clínica}

A mastite clínica pode ser percebida pela perda de apetite da vaca, febre e redução da produção de leite, o úbere fica inchado e avermelhado, e o leite apresenta grumos, pus e outras alterações. Deve ser tratada para não transmitir a infecção a outros animais. Esta mastite pode ser detectada pela eliminação dos primeiros jatos de leite de cada teto em caneca telada ou de fundo escuro. Se houver dúvidas, deve ser realizado o teste do CMT, sigla de "California Mastitis Test". Em ocorrência de mastite que se trata da inflamação do úbere, as células de defesa do animal acontecem do sangue para o leite em grande quantidade. A função destas células é combater as bactérias que estão causando esta mazela e limpar as áreas inflamadas (Dürr, 2012). Em caso de mastite (inflamação do úbere), as células de defesa do animal passam do sangue para o leite em grande quantidade. A função destas células é combater as bactérias que estão causando a mastite e "limpar" as áreas inflamadas (Dürr, 2012).

\section{Mastite subclínica}

A mastite subclínica não apresenta nenhum sintoma, a não ser redução da produção de leite, que quase sempre passa despercebida. Para identificar se a vaca está com mastite subclínica, é necessário observar se houve um aumento da CCS no leite, por meio de análise laboratorial. A maioria dos casos de mastite são da forma subclínica, fazendo com que o produtor muitas vezes não perceba a gravidade do problema em seu rebanho, devido a isso as mastites são de longa duração e causam enormes prejuízos, principalmente pelo leite, que deixa de ser produzido. Por isso, a CCS é uma ferramenta muito importante no manejo do gado leiteiro, pois essa doença altera intensamente a qualidade do leite, reduzindo o rendimento industrial, afetando a validade dos produtos lácteos e o produto oferecido ao consumidor (Dürr, 2012). O tratamento contra mastite utiliza drogas e medicamentos de uso veterinário em geral, passíveis de eliminação pelo leite, motivo pelo qual devem ser afastados da produção pelo período recomendado pelo fabricante, de forma a assegurar que os resíduos da droga não sejam superiores aos níveis fixados em normas específicas (Brasil, 2011).

\section{Conservação do leite}

O leite envasado deve ser imediatamente acondicionado na câmara frigorífica e mantido à temperatura máxima de $4^{\circ} \mathrm{C}$, aguardando a expedição passando por procedimentos específicos para o controle de qualidade da matéria-prima, além de contagem padrão em placas (CPP); contagem de células somáticas (CCS); pesquisas quanto a resíduos de antibióticos; determinação do índice crioscópico (Depressão do Ponto de Congelamento, DPC); determinação do teor de sólidos totais e não gordurosos; determinação da densidade relativa; determinação da acidez titulável; determinação do teor de gordura; e medição da temperatura do leite cru refrigerado (Ribeiro et al., 2011).

Para fazer as análises, as amostras de leite devem ser coletadas em recipientes apropriados, 
limpos ou esterilizados, de acordo com o tipo de análise a ser realizada, e devem ser enviadas ao laboratório sob refrigeração (máximo $7{ }^{\circ} \mathrm{C}$; idealmente, em torno de $4{ }^{\circ} \mathrm{C}$ ) havendo o cuidado para que não haja o congelamento das amostras. Os procedimentos de coleta e transporte de amostras devem ser padronizados, de acordo com normas aceitas internacionalmente, de modo que os resultados alcançados por diferentes laboratórios possam ser comparados entre si. Para obter a confiabilidade dos resultados das análises, dependem, em grande parte, da adoção de metodologias estabelecidas para a coleta, transporte e armazenamento das amostras, sendo importante ressaltar a capacitação do pessoal responsável pela coleta e transporte das amostras de leite; padronização dos procedimentos; escolha de materiais adequados para a coleta, armazenamento e transporte das amostras (especialmente o tipo de frasco, o tipo de conservante e as condições de armazenamento das mesmas); tempo decorrido entre a coleta e a realização das análises e o fornecimento de informações sobre as amostras e o rebanho de origem (Brito et al., 2007).

A indústria deverá enviar, pelo menos uma vez por mês, amostras do leite de cada produtor para análise em laboratório credenciado na Rede Brasileira de Laboratórios de Controle de Qualidade do Leite (RBQL). Os produtores receberão o resultado de suas análises. Através disso o Ministério da Agricultura Pecuária e Abastecimento (MAPA) acompanha a qualidade do leite em cada propriedade rural, e exige que os problemas detectados sejam resolvidos (Dürr, $\underline{2012)}$.

A expedição e transporte do leite envasado deve ser feita sob temperatura máxima de $4^{\circ} \mathrm{C}$, mediante seu acondicionamento apropriado, e transportado ao comércio distribuidor através de veículos com carroçarias munidas de isolamento térmico e dotadas de unidade frigorífica, para alcançar os pontos de venda com temperatura não superior a $7^{\circ} \mathrm{C}$ (Brasil, 2011).

\section{Considerações finais}

O leite por ser um alimento com característica nutricional essencial para o consumo humano é de extrema importância que o produto seja de qualidade para a alimentação adequada, visto que esta matéria prima tem um alto teor de nutrientes e atividade de água, que o torna uma boa fonte para a proliferação de microrganismos. Dessa forma é de suma importância a execução do BPA, desde o momento da ordenha até a sua chegada à granja leiteira para seu beneficiamento, assim evitando possíveis contaminações durante $\mathrm{o}$ processo de obtenção do leite.

\section{Referências bibliográficas}

AGEITEC, Agência Embrapa de Informação tecnológica. 2012. Leite resfriado. Disponível em:<http://www.agencia.cnptia.embrapa.br/ge stor/tecnologia_de_alimentos/arvore/CONT00 0gir19epu02wx5ok05vadr1aw5n9tk.html>. Acesso em: 03.11.2017.

Andrade, K. D., Nascimento Rangel, A. H., Araújo, V. M., Medeiros, H. R., Bezerra, K. C., Bezerril, R. F. \& Lima Júnior, D. M. 2014. Qualidade do leite bovino nas diferentes estações do ano no estado do Rio Grande do Norte. Revista Brasileira de Ciência Veterinária, 21(3).

Arashiro, E., Teodoro, V. \& Miguel, E. 2006. Mastite bovina: importância econômica e tecnológica. Revista do Instituto de Laticínios Cândido Tostes, 61(352), 32-36.

Barancelli, G. V. 2002. Avaliação de métodos para enumeração de microrganismos aeróbios mesófilos e coliformes em leite cru. Piracicaba, SP (Brazil).

Bava, L., Zucali, M., Brasca, M., Zanini, L. \& Sandrucci, A. 2009. Efficiency of cleaning procedure of milking equipment and bacterial quality of milk. Italian Journal of Animal Science, 8(sup2), 387-389.

Brasil, Ministério. da Agricultura, Pecuária e Abastecimento. 2011. Instrução Normativa $n^{\circ}$ 62, de 29 de dezembro de 2011. Regulamento técnico de produção, identidade e qualidade do leite tipo A, regulamento técnico de identidade e qualidade de leite cru refrigerado, regulamento técnico de identidade e qualidade de leite pasteurizado e o regulamento técnico da coleta de leite cru refrigerado e seu transporte a granel. . Diário Oficial da União, Seção 1.

Brasil, Ministério da Agricultura, Pecuária e Abastecimento. 2015. Boas Práticas Agropecuárias.

Brasil, R. B., Silva, M. A. P., Carvalho, T. S., Nicolau, E. S. \& Neves, R. B. S. 2012. Avaliação da qualidade do leite cru em função do tipo de ordenha e das condições de transporte e armazenamento. 
Brito, J., Souza, G., Faria, C., Moraes, L. \& Rodrigues, M. d. C. 2007. Procedimentos para coleta e envio de amostras de leite para determinação da composição e das contagens de células somáticas e de bactérias totais. Embrapa Gado de Leite-Circular Técnica (INFOTECA-E).

Cabral, J. F., da Silva, M. A. P., Brasil, R. B., Carvalho, T. S., Giovannini, C. I. \& Nicolau, E. S. 2013. Efeito de diferentes métodos de coleta sobre os resultados de análise do leite in natura. Revista do Instituto de Laticínios Cândido Tostes, 68(394), 40-44.

Carvalho, T. S., Silva, M., Brasil, R., Cabral, J., Garcia, J. \& Oliveira, A. 2013. Qualidade do Leite Cru Refrigerado Obtido Através de Ordenha Manual e Mecânica. Revista do Instituto de Laticínios Cândido Tostes, v68(390), p05-11.

DAIS, D. A. I. S. 2008. Rules for clean handmilking. Department of Agriculture.

Dürr, J. 2012. Produção de leite conforme Instrução Normativa ${ }^{\circ}$ 62. Senar Brasilia, 14 $-21$.

EMBRAPA, Empresa Brasileira de Pesquisa Agropecuária. 2002. Embrapa gado de leite: Importância Econômica.

EMBRAPA, Empresa Brasileira de Pesquisa Agropecuária. 2011a. Gado de leite: Manejo da Ordenha.

EMBRAPA, Empresa Brasileira de Pesquisa Agropecuária. 2011b. Gado leiteiro: Parecer sobre nota técnica da Câmara Setorial da Cadeia Produtiva do Leite e Derivados de 02/05/2011 sobre a IN51, Juiz de Fora/MG.

Guido, E. S., Silva, E. D. P., Silva, M. C., Takeuchi, K. P. \& Danesi, E. D. G. 2010. Uma abordagem da extensão universitária na melhoria da qualidade do leite na cadeia produtiva do município de Barbosa Ferraz (Paraná). Boletim do Centro de Pesquisa de Processamento de Alimentos, 28(2).

IBGE, I. B. d. G. e. E. 2015. Estatísticas da produção pecuária.

Juliano, R. S., Luz, D. F., Feiden, A., Estrada, C. S. D., Freitas, F. C. \& da Conceição, C. A. 2015. Estudo de caso sobre adoção de boas práticas agropecuárias (BPA) na ordenha junto a um grupo de agricultores em transição agroecológica: resultados preliminares. Cadernos de Agroecologia, 9(4).
Kitchen, B. 1981. Review of the progress of dairy science: Bovine mastitis: milk compositional changes and related diagnostic test. Journal of. Dairy Research, 48, 167-188.

Luz, D. F., Bicalho, F. A., de Oliveira, M. V. M. \& Simões, A. R. P. 2011. Avaliação microbiológica em leite pasteurizado e cru refrigerado de produtores da região do Alto Pantanal Sul-Mato-Grossense. Agrarian, 4(14), 367-374.

Melo, A. F., Silva, M. A. P., de Sousa Carvalho, B., Silva, F. R., do Carmo, R. M. \& Lage, M. E. 2013. Qualidade do leite cru tipo C e refrigerado em sistemas leiteiros tradicionais do sudoeste goiano. Revista do Instituto de Laticínios Cândido Tostes, 68(395), 26-32.

Molineri, A. I., Signorini, M. L., Cuatrín, A. L., Canavesio, V. R., Neder, V. E., Russi, N. B., Calvinho, L. F. 2012. Association between milking practices and psychrotrophic bacterial counts in bulk tank milk. Revista Argentina de microbiologia, 44, 187-194.

Montanhini, M. T. M., Moraes, D. H. M. \& Neto, R. M. 2013. Influência da contagem de células somáticas sobre os componentes do leite. Revista do Instituto de Laticínios Cândido Tostes, 68(392), 18-22.

Nascimento, S. P. \& Raszl, S. M. 2012. Estudo da correlação entre o grau de conformidade às bpa e a segurança do leite. Revista E-Tech: Tecnologias para Competitividade IndustrialISSN-1983-1838, 69-85.

Nero, L. A., Mattos, M. R. d., Beloti, V., Barros, M. d. A., Pinto, J. P. d. A. N., Andrade, N. J. d., Franco, B. D. 2005. Leite cru de quatro regiões leiteiras brasileiras: perspectivas de atendimento dos requisitos microbiológicos estabelecidos pela Instrução Normativa 51. Food Science and Technology (Campinas), 191-195.

PAS Campo, P. A. S., Setor Campo. 2005. Boas Práticas Agropecuárias na Produção Leiteira Parte I. Brasília, DF, Embrapa Transferência de Tecnologia, $39 \mathrm{p}$.

Ribeiro Júnior, J. C., de Lara Shecaira, C., da Silva, F. F., Parren, G. E. \& Beloti, V. 2014. Influência de boas práticas de higiene de ordenha na qualidade microbiológica do leite cru refrigerado. Revista do Instituto de Laticínios Cândido Tostes, 69(6), 395-404.

Ribeiro Junior, J. C., Tamanini, R., Corrêa da Silva, L. C. \& Beloti, V. 2015. Quality of milk 
produced by small and large dairy producers. Semina: Ciências Agrárias, 36(2).

Ribeiro, L. C. A., Arcuri, F. E., Bruneli, T. A. F., Santos, G. G., Brito, F. R. J., Mendonça, C. L., Peixoto, D. C. G. M. 2011. Boas práticas agropecuárias aplicadas à produção do leite.

Saran Netto, A., Fernandes, R. H. R., Azzi, R. \& Lima, Y. V. R. d. 2009. Estudo comparativo da qualidade do leite em ordenha manual e mecânica. J. Health Sci. Inst, 27(4).

Silva, M. A. P. d., Santos, P. A. d., Silva, J. W. d., Leão, K. M., Oliveira, A. N. d. \& Nicolau, E. S. 2010. Variação da qualidade do leite cru refrigerado em função do período do ano e do tipo de ordenha. Revista do Instituto Adolfo Lutz (Impresso), 69(1), 112-118.
Taffarel, L., Costa, P., de Oliveira, N., Braga, G. \& Zonin, W. 2013. Contagem bacteriana total do leite em diferentes sistemas de ordenha e de resfriamento. Arquivos do Instituto Biológico, 80(1), 7-11.

Zafalon, L. F., Pozzi, C. R., Campos, F. P., Arcaro, J. R. P., Sarmento, P. \& Matarazzo, S. V. 2008. Boas práticas de ordenh. São Carlos SP: Embrapa Pecuária Sudeste.

Article History:

Received 16 March 2018

Accepted 4 April 2018

Available online 15 May 2018

License information: This is an open-access article distributed under the terms of the Creative Commons Attribution License 4.0, which permits unrestricted use, distribution, and reproduction in any medium, provided the original work is properly cited. 